\title{
Bondi and beyond. Lessons from three waves of COVID-19 from 2020
}

\author{
Adam Caponª,b, Vicky Sheppearda,b, Nicolas Gonzalez ${ }^{a}$, Jenny

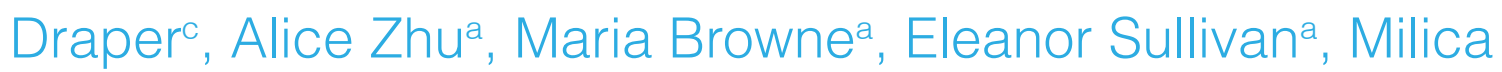 \\ Mihajlovica, Rebecca Rockettd,e and Mark J Ferson ${ }^{a, f}$ \\ a Public Health Unit, South Eastern Sydney Local Health District, NSW, Australia \\ b School of Public Health, University of Sydney, NSW, Australia \\ c Centre for Infectious Diseases and Microbiology Laboratory Services, NSW Health Pathology - Institute of Clinical Pathology and \\ Medical Research, Sydney, NSW, Australia \\ ${ }^{d}$ Centre for Infectious Diseases and Microbiology - Public Health, Westmead Hospital, Sydney, NSW, Australia \\ - Marie Bashir Institute for Infectious Diseases and Biosecurity, University of Sydney, NSW, Australia \\ School of Population Health, UNSW Sydney, Australia \\ g Corresponding author: adam.capon@health.nsw.gov.au
}

\section{Article history}

Publication date: September 2021

Citation: Capon A, Sheppeard V, Gonzalez N, Draper J, Zhu A, Browne M, Sullivan E, Mihajlovic M, Rockett R, Ferson MJ. Bondi and beyond. Lessons from three waves of COVID-19 from 2020. Public Health Res Pract. 2021;31(2):e3132112. https://doi. org/10.17061/phrp3132112

\section{Key points}

- A COVID-19 wave can develop quickly from a single case

- Community-wide lockdowns can be used to control COVID-19 transmission. However, we found a combination of high levels of testing, rapid contact tracing, genomic sequencing and targeted shutdowns along with public adherence to public health advice was successful in controlling waves of COVID-19 experienced in New South Wales, Australia in 2020

\section{Abstract}

Objectives: To describe local operational aspects of the coronavirus disease 2019 (COVID-19) response during the first three waves of outbreaks in New South Wales (NSW), Australia, which began in January, July and December 2020.

Type of program or service: Public health outbreak response.

Methods: Narrative with epidemiological linking and genomic testing.

Results: Epidemiological linking and genomic testing found that during the first wave of COVID-19 in NSW, a large number of community transmissions went undetected because of limited testing for the virus and limited contact tracing of cases. The second wave of COVID-19 in NSW emerged following reintroduction from the second wave in Victoria, Australia in July 2020, and the third wave followed undetected introduction from overseas. By the second and third waves, cases could be more effectively detected and isolated through an increased ability to test and contact trace, and to rapidly genomic sequence severe acute respiratory syndrome coronavirus 2 (SARS-CoV-2) isolates, allowing most cases to be identified and epidemiologically linked. This greater certainty in understanding chains of transmission resulted in control of the outbreaks despite less stringent restrictions on the community, by using a refined strategy of targeted shutdown, restrictions on cases, their close contacts, identified hotspots and venues of concern rather than a whole of community lockdown. Risk assessments of potential transmission sites were constantly updated through our evolving experience with transmission events. However, this refined strategy did leave the potential for large point source outbreaks should any cases go undetected. 
- To prevent the development of new waves of COVID-19 when restrictions are not in place, the community must adhere to public health advice, including getting tested if they have symptoms and signing in to venues
[Addendum] A fourth wave which began in Sydney in June 2021 challenged this strategy due to the more transmissible nature of the Delta variant of SARS-CoV-2.

Lessons learnt: A wave of COVID-19 infections can develop quickly from one infected person. The community needs to remain vigilant, adhering to physical distancing measures, signing in to venues they visit, and getting tested if they have any symptoms. Signing out of venues on exit allows public health resources to be used more efficiently to respond to outbreaks.

\section{The first wave}

On 27 January 2020, the South Eastern Sydney Public Health Unit (PHU), which services a population of approximately 950000 in eastern Sydney, Australia was alerted to its first case of coronavirus disease 2019 (COVID-19). The case was an international student who arrived from Wuhan, China. By the end of March 2020, the PHU had managed 480 COVID-19 cases. One hundred of these cases resided in Bondi and surrounding suburbs, prompting closure of Bondi Beach on 21 March and foreshadowing how life would change under COVID-19.

During March 2020, the PHU rapidly developed a contact tracing team whose members were tasked with tracking down all people who had been identified as contacts of those 480 cases. Guidelines and legislation to combat transmission were still in development and changing rapidly as our understanding of factors in transmission improved (Table 1). On 16 March, a ban on non-essential outdoor gatherings of more than 500 people was put in place in New South Wales (NSW), with those arriving from overseas required to self-isolate for 14 days. ${ }^{1,2}$ On 20 March, Australia closed its borders to all but Australian citizens and residents and on 23 March non-essential businesses in NSW were required to close. ${ }^{3,4}$ From 28 March, overseas arrivals were required to isolate in an approved facility such as a designated hotel and by 31 March indoor and outdoor gatherings in NSW were limited to two people. 5,6 The strategy at the time was suppression of transmission of the virus that caused COVID-19, severe acute respiratory syndrome coronavirus 2 (SARS-CoV-2). There was little expectation that elimination of SARS-CoV-2 was possible. Testing resources were limited and results could take up to 3 days to be issued. Only people linked to a potential source of SARS-CoV-2 and displaying fever or acute respiratory symptoms were eligible for a SARS-CoV-2 test. ${ }^{7}$ Whole genome sequencing of SARS-CoV-2, a technique used to help identify the chain of transmission from one case to another, occurred only in $13 \%$ of cases and on average took 5 days to complete. ${ }^{8}$

The Bondi area (population 19 490) was considered a COVID-19 'hotspot' by April 2020 with 180 COVID-19 cases linked to this area. At the time, the Bondi area had the highest number of cases anywhere in NSW, along with the highest number of cases with an unknown source of infection. ${ }^{9}$ Retrospective epidemiological analysis showed the hotspot was actually an accumulation of seven subclusters accounting for 78 cases plus 102 other cases with incomplete epidemiological links who lived in or visited the Bondi area. The subclusters included an organised event of 400 people (40 cases), a wedding (14 cases), a dinner party (7 cases), a workplace ( 5 cases), a restaurant (4 cases) and two house parties ( 4 cases each). The additional 102 cases probably arose from multiple undetected chains of community transmission. Figure 1 provides an example of the analysis of these subclusters and the identifiable community transmission routes. Whole genome sequencing revealed at least three distinct clusters of SARS-CoV-2 in the area at the time ${ }^{10}$, suggesting introductions into the Bondi area from at least three different sources, with several variants circulating in the South Eastern Sydney region (Figure 2).

The Bondi outbreak represented a large proportion of the first wave of COVID-19 through the South Eastern Sydney population. This first wave ended in May 2020 (Figure 3), with case demographics showing an almost even split of gender and an average age of 42 years (Table 2). During this time the PHU, and NSW Health more generally, increased numbers of contact tracers, enhanced contact tracer training, and increased SARSCoV-2 testing capacity and accessibility. NSW Health increased the centralised contact tracing capacity from zero during the start of the first wave to more than 150 people by the end of the first wave. ${ }^{11}$ 
Table 1. Chronology of interventions undertaken during the three waves

\begin{tabular}{|c|c|}
\hline Date & Intervention \\
\hline \multicolumn{2}{|l|}{2020} \\
\hline 27 January & First wave \\
\hline 16 March & Mass gatherings of 500 or more people in outdoor spaces or 100 people in indoor spaces prohibited. \\
\hline 18 March & $\begin{array}{l}\text { Emergency accommodation and welfare support for cases and close contacts who cannot effectively isolate } \\
\text { implemented. }\end{array}$ \\
\hline 21 March & Four square metre per person rule introduced. \\
\hline 20 March & Australian border closure. \\
\hline 23 March & Non-essential businesses close in NSW. \\
\hline 28 March & Mandatory hotel quarantine for overseas arrivals introduced. \\
\hline 31 March & NSW lockdown - indoor and outdoor gathering limited to two people in NSW. \\
\hline 17 April & $\begin{array}{l}\text { Definition of infectious case increased from } 24 \text { to } 48 \text { hours from symptom onset to ensure greater capture of all } \\
\text { close contacts. }\end{array}$ \\
\hline 24 April & Laboratory capacity for testing doubles from an average of 4000 to 8000 tests per day. \\
\hline 15 April & $\begin{array}{l}\text { Easing of restrictions in NSW begins - no more than } 10 \text { people at any time to consume food or drinks on } \\
\text { commercial premises. Outdoor public spaces are open. Gatherings of up to } 10 \text { people allowed. Contact } \\
\text { information required to be recorded at events. }\end{array}$ \\
\hline 20 May & $\begin{array}{l}\text { How to investigate the source of infection for cases with no known source identified is codified in national public } \\
\text { health guidelines. }\end{array}$ \\
\hline 1 June & $\begin{array}{l}\text { Food and drink premises capped at } 50 \text { customers provided there is } 4 \text { square metres of space per person. } \\
\text { Premises must have a COVID-19 safety plan and record names and contact details of each customer. }\end{array}$ \\
\hline 1 July & $\begin{array}{l}\text { Public bars must ensure the maximum number of customers is } 300 \text { people provided there is } 4 \text { square metres } \\
\text { space per person. A maximum of } 10 \text { people only for any venue booking. }\end{array}$ \\
\hline
\end{tabular}

\begin{tabular}{ll}
\hline July & Second wave \\
2 July & NSW Government restricts entry into NSW of non-NSW residents if they have attended a COVID-19 hotspot \\
& within the past 14 days, specifically the state of Victoria. A mandatory 14-day quarantine is imposed for returning \\
& residents.
\end{tabular}

8 July NSW enacts border controls between NSW and Victoria.

23 July COVID-19 'safety hygiene marshal' required for certain premises.

30 July Sewage surveillance for SARS-CoV-2 begins.

31 July Immediate SARS-CoV-2 testing for all close contacts required by national public health guidelines.

1 August Hospitality venues and gymnasiums must register as COVID-19 safe businesses.

30 August NSW Health advises mask wearing on public transport.

13 October Immediate plus day 12 SARS-CoV-2 testing for all close contacts adopted in NSW public health guidelines.

20 November Mandatory electronic capture of customer details at venues.

23 November Repeal of border controls between states of NSW and Victoria.

7 December Density restrictions relaxed to require 2 square metres per person indoors except at gyms and nightclubs (where 4 square metres per person is required).

\begin{tabular}{|c|c|}
\hline Mid-December & Third wave \\
\hline 14 December & $\begin{array}{l}\text { Daily saliva testing required for quarantine facility workers and transportation providers associated with airline } \\
\text { crew. }\end{array}$ \\
\hline 19 December & Restrictions on people in Syndey's Northern Beaches local government area to contain the spread of COVID-19. \\
\hline 20 December & $\begin{array}{l}\text { SARS-CoV-2 testing of all casual contacts adopted in NSW public health guidelines. } \\
\text { Density restrictions tightened to require } 4 \text { square metres per person in indoor areas in Greater Sydney. }\end{array}$ \\
\hline 30 December & Limit of 300 people at a hospitality venue and no more than 5 visitors per day for greater Sydney. \\
\hline \multicolumn{2}{|l|}{2021} \\
\hline 3 January & Mandatory face coverings required in certain settings. \\
\hline
\end{tabular}


Figure 1. Example of epidemiological links between March 2020 Bondi COVID-19 subclusters following introduction from undetected community transmission

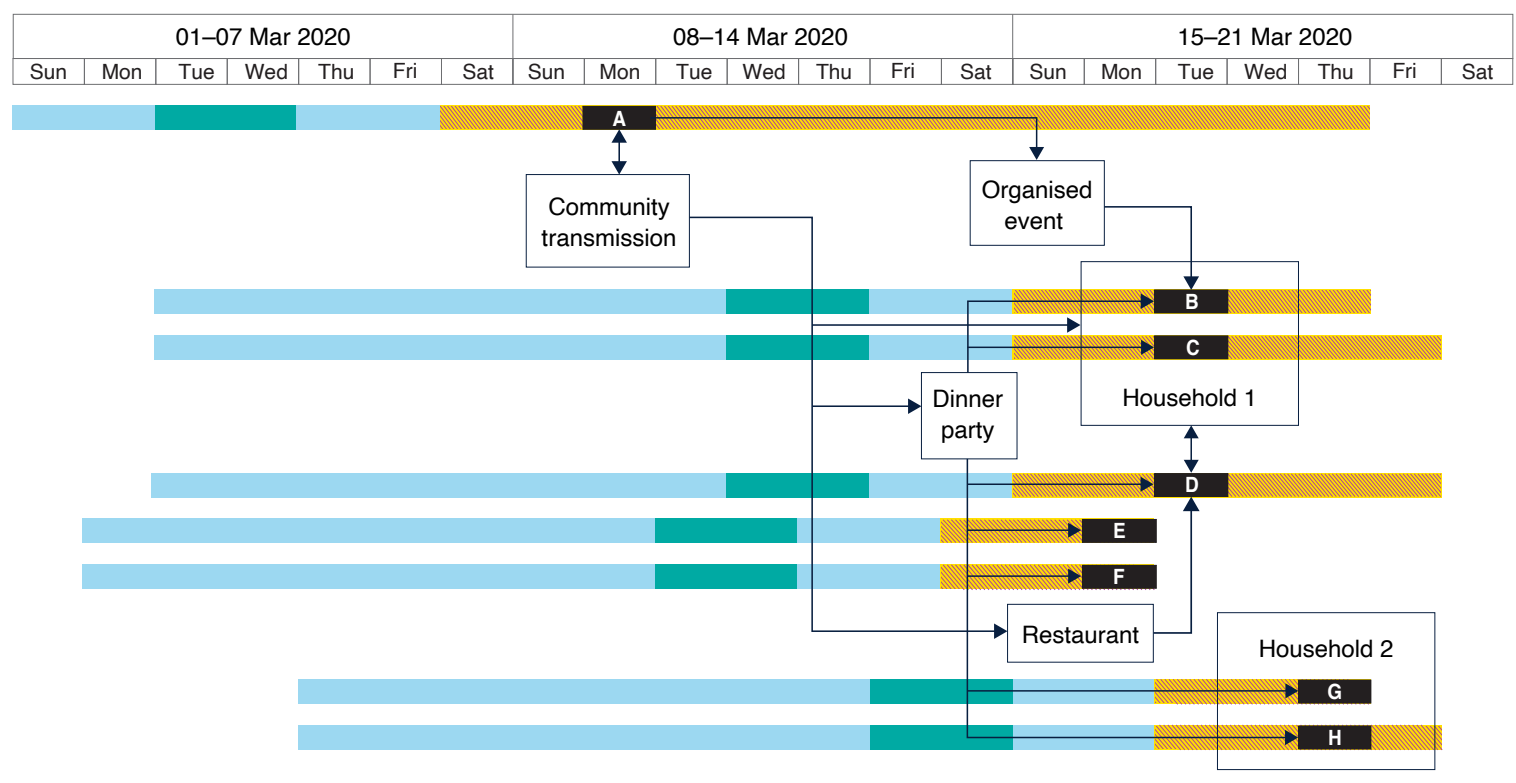

A, B, C... Day of symptom onset for notified cases

Case incubation period

Days when exposure to SARS-CoV-2 was most likely

Case infectious period

Linking to other cases and venues

Exposure points

Figure 2. Epidemiological fishplot (GitHub 2021) ${ }^{10}$ showing the progression and number of genomic variants across the three waves

$\frac{\text { Jan }}{1825} \frac{\text { Feb }}{18152229} \frac{\text { Mar }}{7142128} \frac{\text { Apr }}{4111825} \frac{\text { May }}{29162330} \frac{\text { Jun }}{6132027} \frac{\text { Jul }}{4111825} \frac{\text { Aug }}{18152229} \frac{\text { Sep }}{5121926310172431} \frac{\text { Oct }}{7142128} \frac{\text { Dec }}{5121926} \frac{\text { Jan }}{29}$

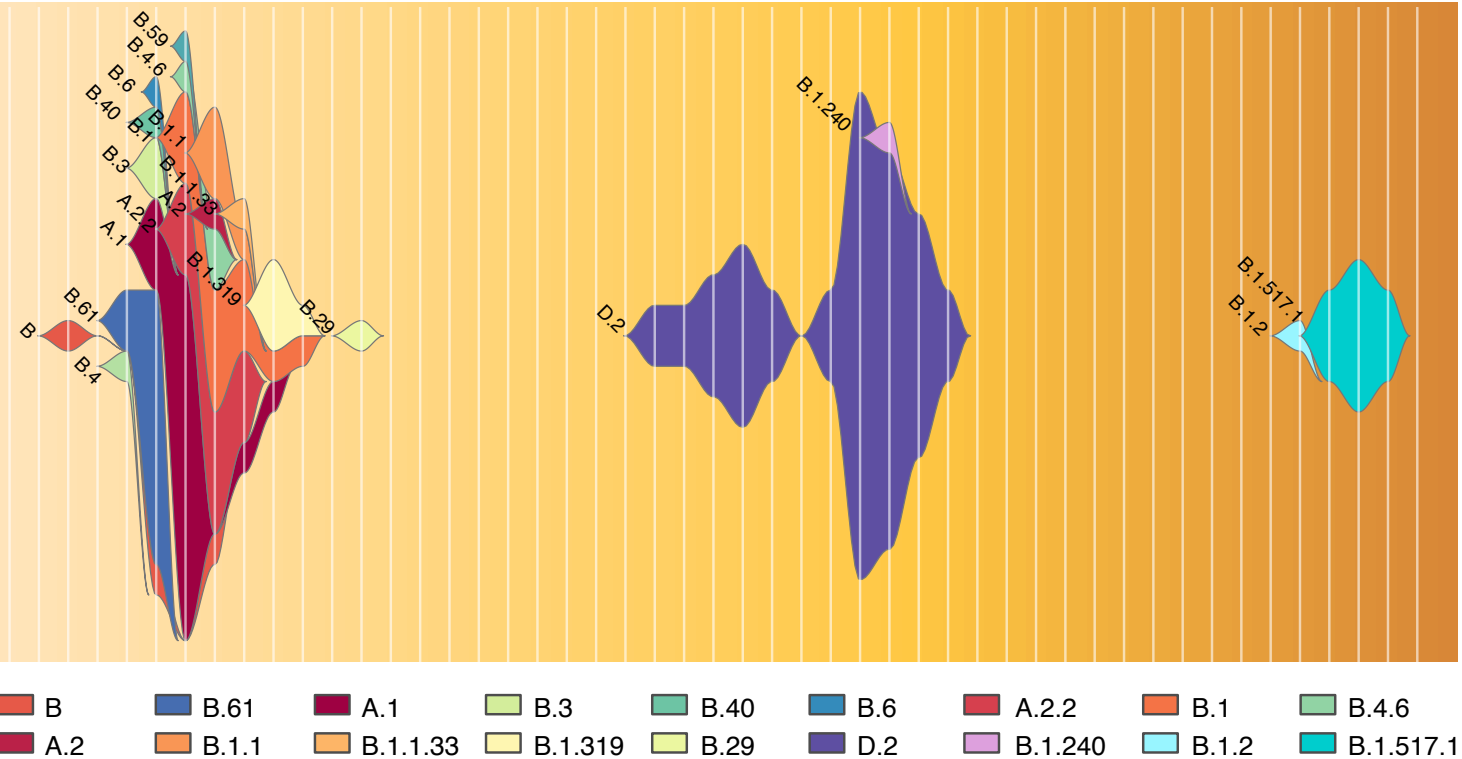

Note: The height at each timepoint represents the total number of cases with a symptom onset in that week, colour coded by PANGO lineage. The different colours highlight different sources of SARS-CoV-2, with the first wave driven by multiple sources while the second and third wave by a single source. The maximum number of sequenced cases was 20 for the week ending 21 March 2020 , and 16 for the week of 29 August 2020. Lineages were calculated using the software package, pangolin (San Franscisco, CA: GitHub; 2021). Genomes were obtained as per Rockett et al. ${ }^{8}$ 
Figure 3. COVID-19 case notifications for the South Eastern Sydney region showing the three waves, January 2020 - January 2021

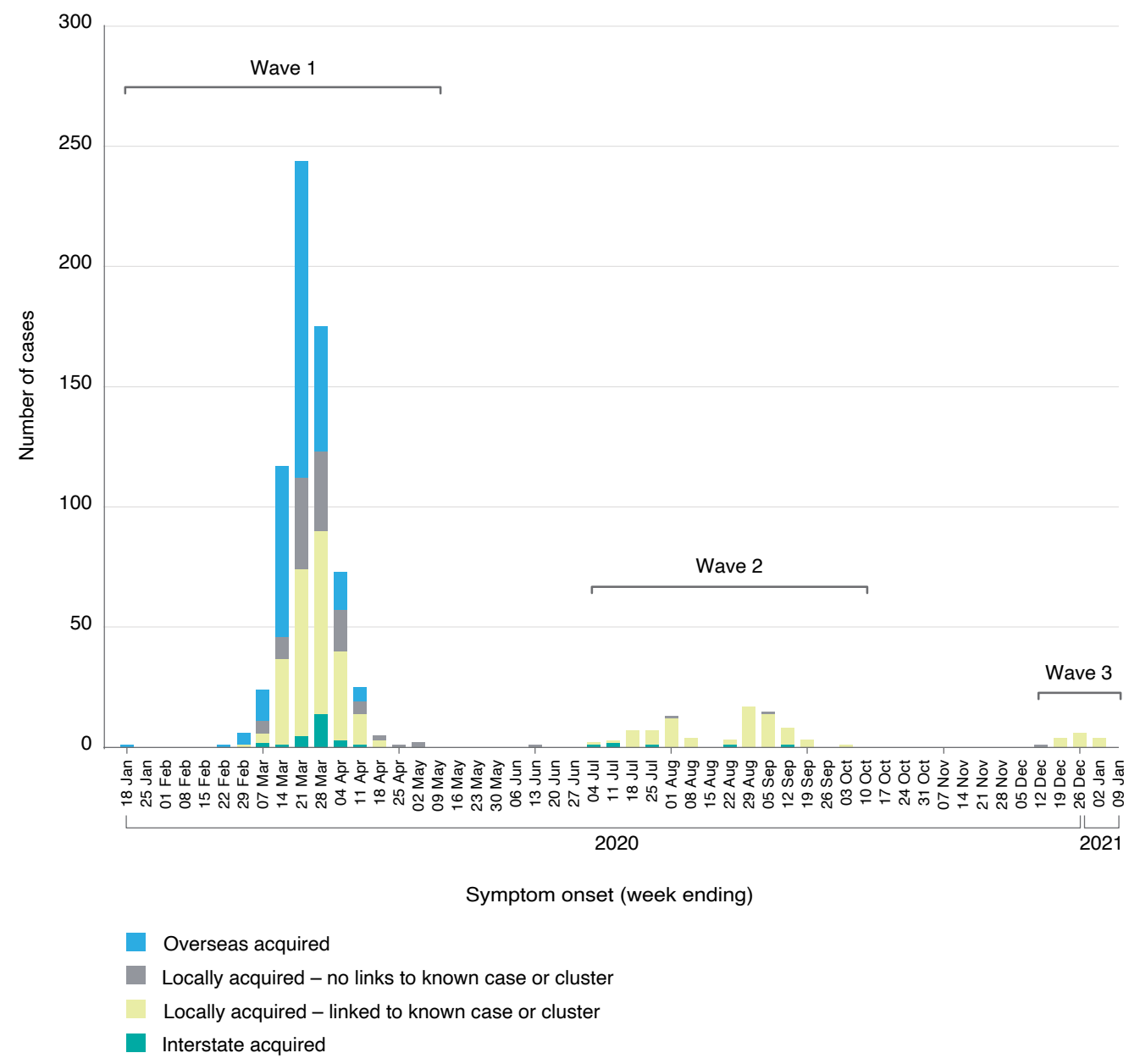

Note: This figure does not include overseas acquired cases after 11 April 2020 as, due to mandatory hotel quarantine implemented on March 28, these cases could not trigger community transmission. The grey 'Locally acquired - no links to known case or cluster' indicates unlinked community transmission cases.

Table 2. Case demographics across the three waves

\begin{tabular}{lccc}
\hline & $\begin{array}{c}\text { Wave 1 } \\
(n=673)\end{array}$ & $\begin{array}{c}\text { Wave 2 } \\
(n=81)\end{array}$ & $\begin{array}{c}\text { Wave 3 } \\
(n=15)\end{array}$ \\
\hline $\begin{array}{l}\text { Mean age } \\
\text { (range), years }\end{array}$ & $42(2-95)$ & $44(13-88)$ & $39(0-75)$ \\
\hline
\end{tabular}

\section{Gender}

\begin{tabular}{llll} 
Female \% & 52 & 56 & 60 \\
Male \% & 48 & 44 & 40 \\
\hline
\end{tabular}

\section{The second wave}

On 10 July 2020 two cases of COVID-19 were discovered in NSW and were linked to a hotel in western Sydney following travel of one of the cases from an outbreak in Melbourne, Victoria. ${ }^{12}$ Soon after, cases appeared in South Eastern Sydney and were subsequently linked to outbreaks in restaurants, gymnasiums and workplaces throughout the region. ${ }^{13,14}$ By this stage testing capacity for SARS-CoV-2 had improved and anyone who had even the slightest symptoms of COVID-19 was urged to get tested, along with all close contacts of confirmed cases. ${ }^{15,16}$ Almost every new case of COVID-19 in NSW was able to be traced back to a source (559 of 608 cases), meaning little or no unlinked community transmission was occurring during this second wave. ${ }^{17-}$ ${ }^{20}$ Capacity for genomic testing had improved and was used to confirm these links in near-real time with $73 \%$ of South Eastern Sydney cases genomically tested. The genomic testing showed the cases were genomically clustered and therefore from the same source (Figure 2). Epidemiological clusters of COVID-19 cases were being routinely identified, their sources isolated, and contacts quarantined. As a result, restrictions on the population were less severe than the first wave. Venues that entertained a large number of people such as pubs, clubs, gymnasiums and restaurants were still able to trade, provided they adhered to COVID rules that included recording the contact details of all patrons (Table 1). ${ }^{21}$ No longer was the strategy about supressing 
the virus through a whole population lockdown, it was now about elimination of the virus through targeted shutdown and restrictions on cases, their close contacts, identified hotspots and venues of concern.

\section{The third wave}

By mid-October 2020, the second wave had come to an end for the South Eastern Sydney region. It wasn't until mid-December that cases, with links to a cluster identified in Northern Sydney, again began appearing in the region. Genomic testing identified that the virus had originated from overseas, essentially a recently imported virus and not one that had been previously circulating in NSW. Like the second wave, only a small number of cases were unable to be epidemiologically linked to a known source in NSW (12 of 206), suggesting little undetected community transmission was occurring. ${ }^{22}$ Eighty percent of South Eastern Sydney cases were genomically tested with all but one case linked to the one variant (Figure 2). Similar NSW government strategies of targeted shutdown, case isolation and close contact quarantine, and restrictions on identified hotspots and venues of concern, were in place, with the addition of face masks in certain settings. ${ }^{23}$

\section{Discussion}

The speed at which COVID-19 spread across the world and into local regions caught everyone off guard. A lack of resources and policies required to respond to the first wave in NSW led to uncontrolled community transmission. For example, limited testing availability meant an unknown number of COVID-19 cases went undiagnosed, and were thus not isolated, with contact tracing unable to be conducted. To combat this, the NSW Government imposed strict lockdown measures on the community, designed to eliminate any nonessential contact between people. ${ }^{5}$ This strategy's purpose was to deny SARS-CoV-2 the opportunity to spread within the broader community. The strict lockdown measures imposed in March 2020 and the adherence by the public to these measures broke the chain of community transmission, and NSW became essentially SARS-CoV-2 free.

SARS-CoV-2 testing and contact tracing resources had been increased immensely by the time the second wave developed in NSW, with a large increase in testing rates in the second and third wave compared with the first (Figure 4). This led to a new NSW Government strategy that allowed continued easing of movement and gathering restrictions, but which posed greater challenges for contact tracing. During the first wave, once strict lockdown measures were in place, contacts were mostly limited to household contacts or close friends. The less stringent restrictions during the second wave meant a case could attend a venue, such as a pub or a club, and have contact with more than 1000 patrons. There was potential for explosive point source outbreaks.

To prevent these outbreaks, PHU contact tracers were required to identify whether patrons at these venues were considered close contacts of the COVID-19 case and therefore required to isolate for 14 days. A close

Figure 4. Weekly South Eastern Sydney population test rate of SARS-CoV-2 tests per 100000 across the three waves, January 2020 - January 2021

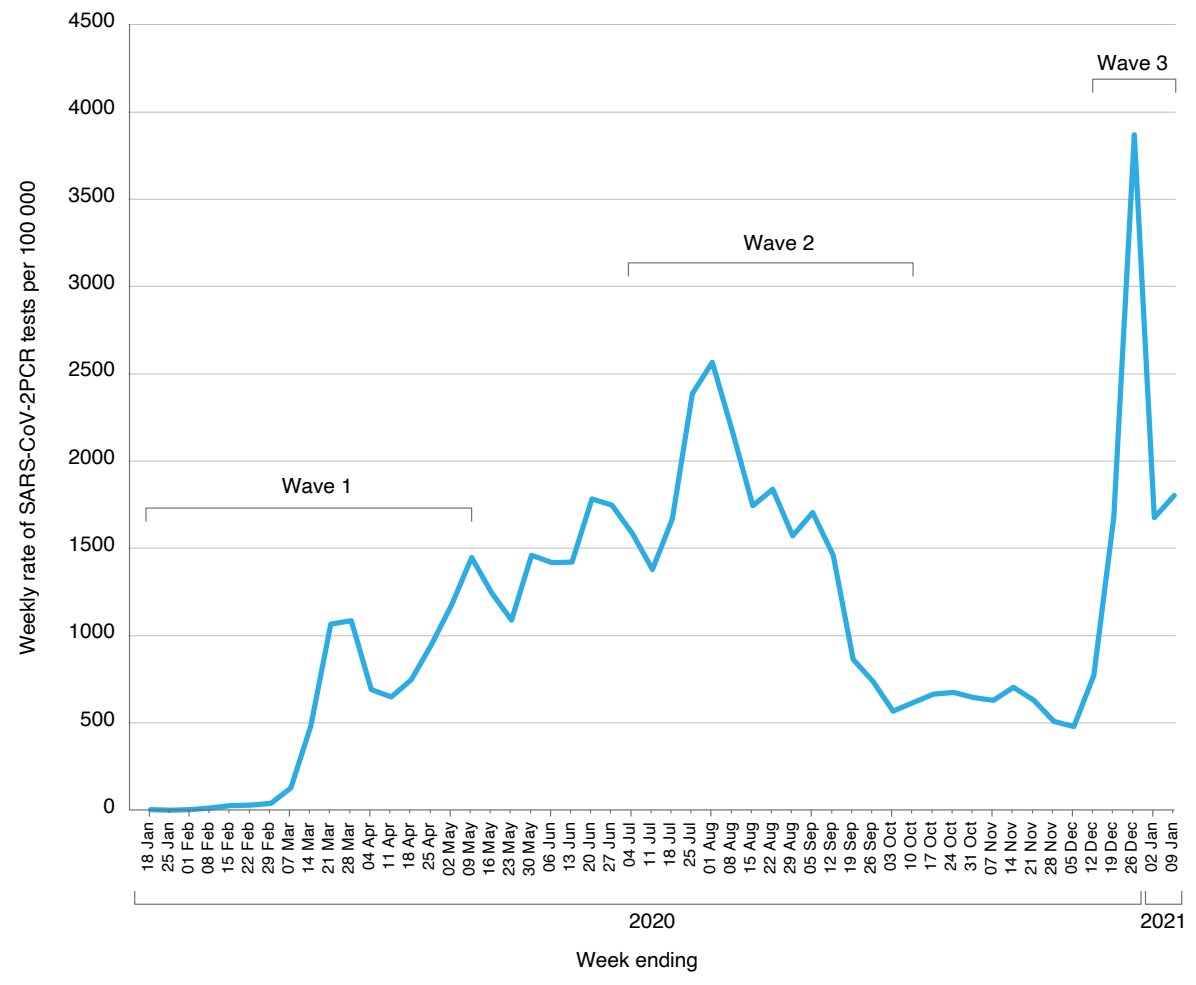


contact in these venues was initially determined by applying a national definition - 15 minutes cumulative face-to-face contact with the case or 2 hours in the same room as the case. ${ }^{24}$ However, it wasn't long before the inadequacies of this approach were realised and a refined risk assessment approach was used in these environments. This approach, subsequently adopted in state and national guidelines, was based on experience of active transmission in similar settings. ${ }^{25}$ In essence, this could mean the time period used to define a close contact could be shorter or longer depending on other risk factors present. On an individual level, one factor that could influence being deemed a close contact or not would be the risk assessor having an objective measure of when the individual may have entered and exited the venue. Without these objective measures available, an extra level of precaution needed to be applied to the risk assessment. Thus 'signing in and out' of a venue could prove the difference between an individual being quarantined for 14 days or not. 'Signing out' from a venue by a patron would also significantly reduce the workload of contact tracers because patrons with documented evidence of spending shorter times at the venue would not need to be contacted.

From the authors' observations, success in controlling the spread of SARS-CoV-2 through the first, second and third waves was based on limiting unlinked or undetected community transmission, and the rapid development of, and universal access to, SARS-CoV-2 testing and contract tracing resources. Limiting community transmission would also not have been possible without the high level of community compliance with public health advice to get tested for SARS-CoV-2 and isolate.

\section{Implications}

One year later, NSW is in a much stronger position to respond to the COVID-19 pandemic than it was in January 2020. SARS-CoV-2 testing capacity has increased, and this is mirrored by the public health resources required to identify, trace and isolate COVID-19 cases and their contacts. Policies such as mandatory hotel quarantine for returned travellers are now in place to limit the potential importation of SARS-CoV-2 from overseas. However, the second wave taught us that only one or two cases within our community can lead to major outbreaks. Important measures for control include the community adhering to physical distancing measures, signing in and out of venues they visit, and getting tested if they have even the mildest of symptoms.

\section{Addendum}

As this paper is going to publication a fourth wave of COVID-19 infection is being experienced in Sydney (June 2021-present). This wave is driven by the Delta variant of SARS-CoV-2, known to be more transmissible than other variants. ${ }^{26}$ The transmissibility of the Delta variant is testing the ability of public health action to control this wave. Although complete control of the current wave is proving challenging, it has been noted that the current public health actions are having an impact, with estimates of up to 10 times reduction in spread when compared with no public health intervention. ${ }^{27}$

\section{Acknowledgements}

We wish to acknowledge the staff at South Eastern Sydney Public Health Unit who participated in the public health response during the three waves of infection, and the genomic expertise provided by Alicia Arnott, Carl Banting, Mailie Gall, Andrew Ginn, Karen-Ann Gray, Clement Lee, Elena Martinez, Eby Sim, Qinning Wang, Sharon Chen, Dominic Dwyer, Jen Kok, and Vitali Sintchenko from NSW Health Pathology ICPMR Microbial Genomics Laboratory, as well as Rajat Dhakal, Connie Lam, Rosemarie Sadsad and Verlaine Timms from the Centre for Infectious Diseases and Microbiology - Public Health, Westmead Hospital.

\section{Peer review and provenance}

Externally peer reviewed, not commissioned.

\section{Competing interests}

None declared.

\section{Author contributions}

AC undertook conceptualisation, data analysis and led the writing of the manuscript. VS provided conceptualisation, and drafted and edited the manuscript. NG, AZ, MB, ES and MM conducted data analysis and drafting of the manuscript. JD and RR provided genomic analysis, and MF drafted and edited the manuscript.

\section{References}

1. NSW Minister for Health and Medical Research. Public health (COVID-19 public events) Order 2020 (15 March 2020). Sydney: NSW Government; 2020 [cited 2021 Feb 1]. Available from: www.legislation.nsw.gov.au/ file/Public\%20Health\%20(COVID-19\%20Public\%20 Events)\%20Order\%202020.pdf

2. Morrison S. Coronavirus measures endorsed by National Cabinet - media release 16 Mar 2020. Canberra: Prime Minister of Australia; 2020 [cited 2021 Feb 1]. Available from: www.pm.gov.au/media/coronavirus-measuresendorsed-national-cabinet 
3. NSW Minister for Health and Medical Research. Public health (COVID-19 places of social gathering) order 2020 (dated 23 March 2020). Sydney: NSW Government; 2020 [cited 2021 Feb 1]. Available from: legislation.nsw.gov. au/file/Public\%20Health\%20(COVID-19\%20Places\%20 of\%20Social\%20Gathering)\%200rder\%202020.pdf

4. Morrison S. Border restrictions - media release 19 Mar 2020. Canberra: Prime Minister of Australia; 2020 [cited 2021 Feb 1]. Available from: www.pm.gov.au/ media/border-restrictions\#: :text=Australia\%20is\%20 closing\%20its\%20borders,spouses\%2C\%20legal\%20 guardians\%20and\%20dependants

5. NSW Minister for Health and Medical Research. Public health (COVID-19 restrictions on gathering and movement) order 2020 (30 March 2020). Sydney: NSW Government; 2020 [cited 2021 Feb 1]. Available from: legislation.nsw.gov.au/file/Public\%2OHealth\%20 (COVID-19\%20Restrictions\%20on\%20Gathering\%20 and\%20Movement)\%20Order\%202020.pdf

6. Australian Government Department of Health. National review of hotel quarantine - a review of quarantine systems and processes in all states and territories except Victoria. Canberra: Australian Government; 2020 [cited 2021 Aug 20]. Available from: www.health.gov.au/sites/ default/files/documents/2020/10/national-review-of-hotelquarantine.pdf

7. Communicable Diseases Network Australia. Coronavirus disease 2019 (COVID-19) CDNA national guidelines for public health units - version 1.18 (10 March 2020). Canberra: Australian Department of Health; 2020 [cited 2021 Aug 20]. Available from: www.wnswphn.org.au/ uploads/documents/Resources/Coronavirus/interimCOVID-19-SoNG-v2.0.pdf

8. Rockett RJ, Arnott A, Lam C, Sadsad R, Timms V, Gray K-A, et al. Revealing COVID-19 transmission in Australia by SARS-CoV-2 genome sequencing and agent-based modeling. Nat Med. 2020;26(9):1398-404.

9. NSW Health. COVID-19 (coronavirus) statistics 01 April 2020. Sydney: NSW Government; 2020 [cited 2021 Feb 1]. Available from: www.health.nsw.gov.au/news/ Pages/20200401_00.aspx

10. GitHub. Epifish. San Francisco: GitHub; 2021 [cited 2021 Aug 20]. Available from: github.com/learithe/epifish

11. NSW Health. Contact tracing capabilities ramp up to fight COVID-19 (16 April 2020). Sydney: NSW Government; 2020 [cited 2021 Feb 1]. Available from: www.health.nsw. gov.au/news/Pages/20200416_01.aspx

12. NSW Health. COVID-19 weekly surveillance in NSW epidemiological week 28, ending 11 July 2020. Sydney: NSW Government; 2020 [cited 2021 Aug 20]. Available from: www.health.nsw.gov.au/Infectious/covid-19/ Documents/covid-19-surveillance-report_160720.pdf
13. NSW Health. COVID-19 weekly surveillance in NSW - epidemiological week 37, ending 12 September 2020. Sydney: NSW Government; 2020 [cited 2021 Aug 20]. Available from: www.health.nsw.gov.au/ Infectious/covid-19/Documents/covid-19-surveillancereport-20200912.pdf

14. Capon A, Houston J, Rockett R, Sheppeard V, Chaverot S, Arnott A, et al. Risk factors leading to COVID-19 cases in a Sydney restaurant. Aust N Z J Public Health. 2021 Jun 28. doi: 10.1111/1753-6405.13135. Online ahead of print.

15. NSW Health. COVID-19 (coronavirus) statistics (1 July 2020). Sydney: NSW Government; 2020 [cited 2021 Feb 1]. Available from: www.health.nsw.gov.au/news/ Pages/20200701_00.aspx

16. NSW Health. Coronavirus disease 2019 (COVID-19) CDNA national guidelines for public health units Appendix A: Jurisdiction specific issues NSW - reviewed 14 Aug 2020. NSW Health; 2020 [cited 2021 Aug 20]. Available from: www.health.nsw.gov.au/Infectious/ controlguideline/Documents/song-appendix.pdf

17. NSW Health. COVID-19 weekly surveillance in NSW epidemiological week 30, ending 25 July 2020. Sydney: NSW Government; 2020 [cited 2021 Aug 20]. Available from: www.health.nsw.gov.au/Infectious/covid-19/ Documents/covid-19-surveillance-20200730.pdf

18. NSW Health. COVID-19 weekly surveillance in NSW - epidemiological week 34, ending 22 August 2020. Sydney: NSW Government; 2020 [cited 2021 Aug 20]. Available from: www.health.nsw.gov.au/ Infectious/covid-19/Documents/covid-19-surveillancereport-20200822.pdf

19. NSW Health. COVID-19 weekly surveillance in NSW - epidemiological week 38, ending 19 September 2020. Sydney: NSW Government; 2020 [cited 2021 Aug20]. Available from: www.health.nsw.gov.au/ Infectious/covid-19/Documents/covid-19-surveillancereport-20200919.pdf

20. NSW Health. COVID-19 weekly surveillance in NSW epidemiological week 42, ending 17 October 2020. NSW Government; 2020 [cited 2021 Aug 20]. Available from: www.health.nsw.gov.au/Infectious/covid-19/Documents/ covid-19-surveillance-report-20201017.pdf

21. NSW Minister for Health and Medical Research. Public health (COVID-19 restrictions on gathering and movement) order (No 4) 2020 - amended 16 July 2020. Sydney: NSW Government; 2020 [cited 2021 Feb 4]. Available from: legislation.nsw.gov.au/file/Public\%20 Health\%20(COVID-19\%20Restrictions\%20on\%20 Gathering\%20and\%20Movement)\%20Order\%20(No\%20 4)\%202020_200717.pdf

22. NSW Health. COVID-19 weekly surveillance in NSW epidemiological week 1, ending 9 January 2021. Sydney: NSW Government; 2021 [cited 2021 Aug 20]. Available from: www.health.nsw.gov.au/Infectious/covid-19/ Documents/covid-19-surveillance-report-20210109.pdf 
23. NSW Minister for Health and Medical Research. Public health (COVID-19 mandatory face coverings) order 2021 (2 January 2021). Sydney: NSW Government; 2021 [cited 2021 Feb 5]. Available from: legislation.nsw.gov.au/file/ Public\%20Health\%20\%28COVID-19\%20Mandatory\%20 Face\%20Coverings\%29\%20Order\%202021.pdf

24. Communicable Diseases Network Australia. Coronavirus disease 2019 (COVID-19) CDNA national guidelines for public health units - version 3.3 dated 22 June 2020. Canberra: Australian Department of Health; 2020 [cited 2021 Aug 20]. Available from: agedcare.royalcommission. gov.au/system/files/2020-10/CTH.4000.0001.1964.pdf
25. NSW Health. SoNG appendix coronavirus disease (COVID-19) CDNA national guidelines for public health units (1 January 2021). Sydney: NSW Government; 2021 [cited 2021 Aug 20]. Available from: www.health.nsw.gov. au/Infectious/controlguideline/Documents/song-appendix. pdf

26. Campbell $F$ et al. Increased transmissibility and global spread of SARS-CoV-2 variants of concern as at June 2021. Euro Surveill. 2021;26(24).

27. Bennett C. It might not feel like it as cases rise, but NSW is controlling Delta. The Guardian (Australian edition) [cited 2021 Aug 23]. Available from: www.theguardian. com/commentisfree/2021/aug/20/it-might-not-feel-like-itas-cases-rise-but-nsw-is-controlling-delta

\section{Copyright: (c) (i) (2) (2)}

(C) 2021 Capon et al. This article is licensed under the Creative Commons Attribution-NonCommercial-ShareAlike 4.0 International Licence, which allows others to redistribute, adapt and share this work non-commercially provided they attribute the work and any adapted version of it is distributed under the same Creative Commons licence terms. See: www.creativecommons.org/licenses/by-nc-sa/4.0/ 